\title{
Case of Penile Malignant Peripheral Nerve Sheath Tumor in a Twenty-Year-Old Male with Neurofibromatosis Type 1
}

\author{
Orchid Djahangirian $^{1 *}$, Ngoc-Anh Tran ${ }^{1}$, Lilibeth Torno ${ }^{2}$ and Antoine Khoury ${ }^{1}$ \\ ${ }^{1}$ Division of Urology, Department of Surgery, CHOC Children's Hospital of Orange County, University of \\ California, Irvine, USA \\ ${ }^{2}$ Division of Oncology, CHOC Children's Hospital of Orange County, University of California, Irvine, USA
}

*Corresponding author: Orchid Djahangirian, Division of Urology, Department of Surgery, CHOC Children's Hospital of Orange County, University of California, Irvine, USA

\section{Introduction}

Malignant peripheral nerve sheath tumors (MPNSTs) arise from the peripheral nerves and are derived from Schwann cells. They represent $5-10 \%$ of all soft tissue sarcomas (STS) and occur in only $0.001 \%$ of the general population [1]. The prevalence of MPNST is significantly increased, however, in patients with neurofibromatosis type 1 (NF1), who have an estimated $8-13 \%$ lifetime risk for developing the tumor from pre-existing plexiform neurofibromas [2]. Up to 50\% of MPNSTs are associated with NF1, 11\% with irradiation presenting an average of 17 years post-radiation, while the remainder are sporadic. The combination of these risk factors is exponential [1]. MPNST associated with NF1 typically presents at an earlier age with larger tumors larger of higher grade [3].

MPNSTs historically present diagnostic and therapeutic challenges due to their variable histologic appearance and highly aggressive nature [1]. Management of MPNST of the penis is especially challenging as only 8 cases are reported in the literature and combinations of surgery, chemotherapy and radiation yield variable outcomes. We report the case of a 20-year-old male with NF1, history of total body irradiation, and MPNST of the mediastinum, who presented with a rapidly enlarging penile mass. This is the largest reported penile MPNST, the first to occur in the setting of total body irradiation and multifocal MPNST, and the first to be treated with adjuvant targeted therapy.

\section{Case Report}

The patient's past medical history was significant for juvenile myelomonocytic leukemia (JMML) that was treated at the age of three years with chemotherapy, total body irradiation and splenectomy and bone marrow transplantation. The patient was clinically diagnosed with NF1 on the basis of multiple café au lait macules, cutaneous neurofibromas, and axillary and inguinal freckling.

At the age of 19 years, imaging performed to evaluate a two-week history of coughing revealed a right paratracheal mediastinal mass. Histologic findings on medianoscopic biopsy were consistent with an intermediate-grade MPSNT. The mass was adherent to the bronchi and resection would have involved pneumonectomy. Given the patient's comorbidities, his family declined surgery. The patient underwent a course of radiation therapy with $50 \mathrm{~Gy}$ to the tumor bed and $20 \mathrm{~Gy}$ boost that was complicated by radiation pneumonitis. He was subsequently started on pazopanib, a tyrosine kinase inhibitor.

One year following initiation of pazopanib for the mediastinal mass, which had remained stable in size, a high-uptake penile mass first appeared on follow-up 18-fluoro-2-deoxyglucose (FDG) PET-CT scan, among the lumbar and sacral plexus neurofibromas. Five months later, a repeat FDG PET-CT scan revealed a significant increase in size and metabolic activity concerning for sarcomatous degeneration of a peripheral nerve

Citation: Djahangirian O, Ngoc-Anh T, Torno L, Khoury A (2018) Case of Penile Malignant Peripheral Nerve Sheath Tumor in a Twenty-Year-Old Male with Neurofibromatosis Type 1. Int Arch Urol Complic 4:044. doi.org/10.23937/2469-5742/1510044

Accepted: October 09, 2018: Published: October 11, 2018

Copyright: ( 2018 Djahangirian O, et al. This is an open-access article distributed under the terms of the Creative Commons Attribution License, which permits unrestricted use, distribution, and reproduction in any medium, provided the original author and source are credited. 


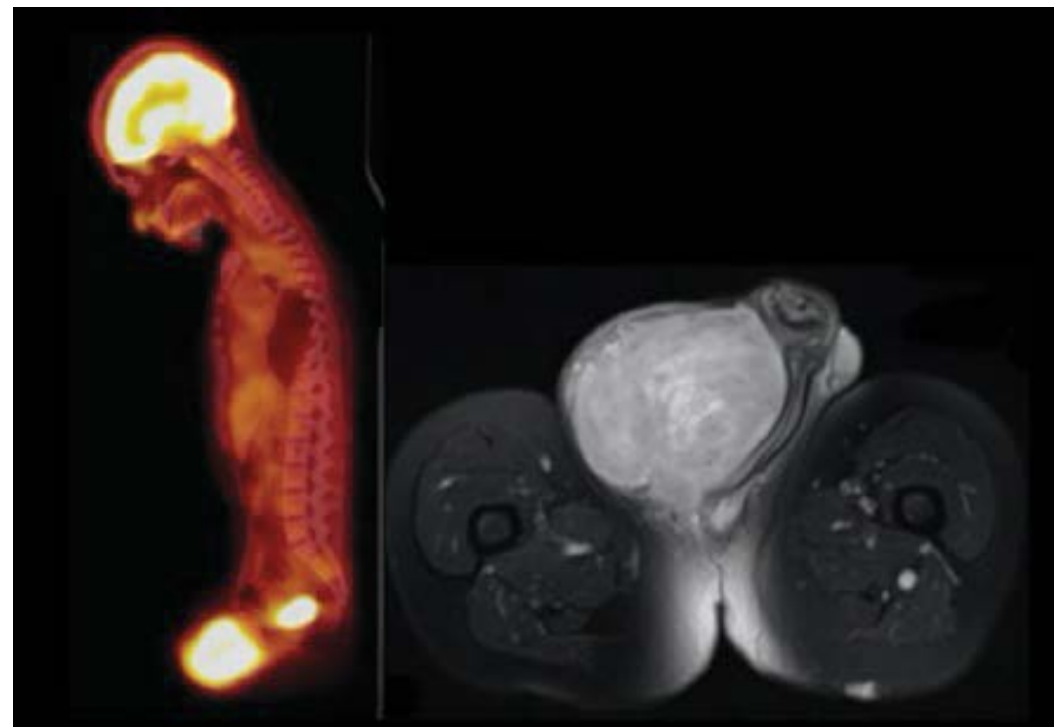

Figure 1: PET-CT left; MRI right.

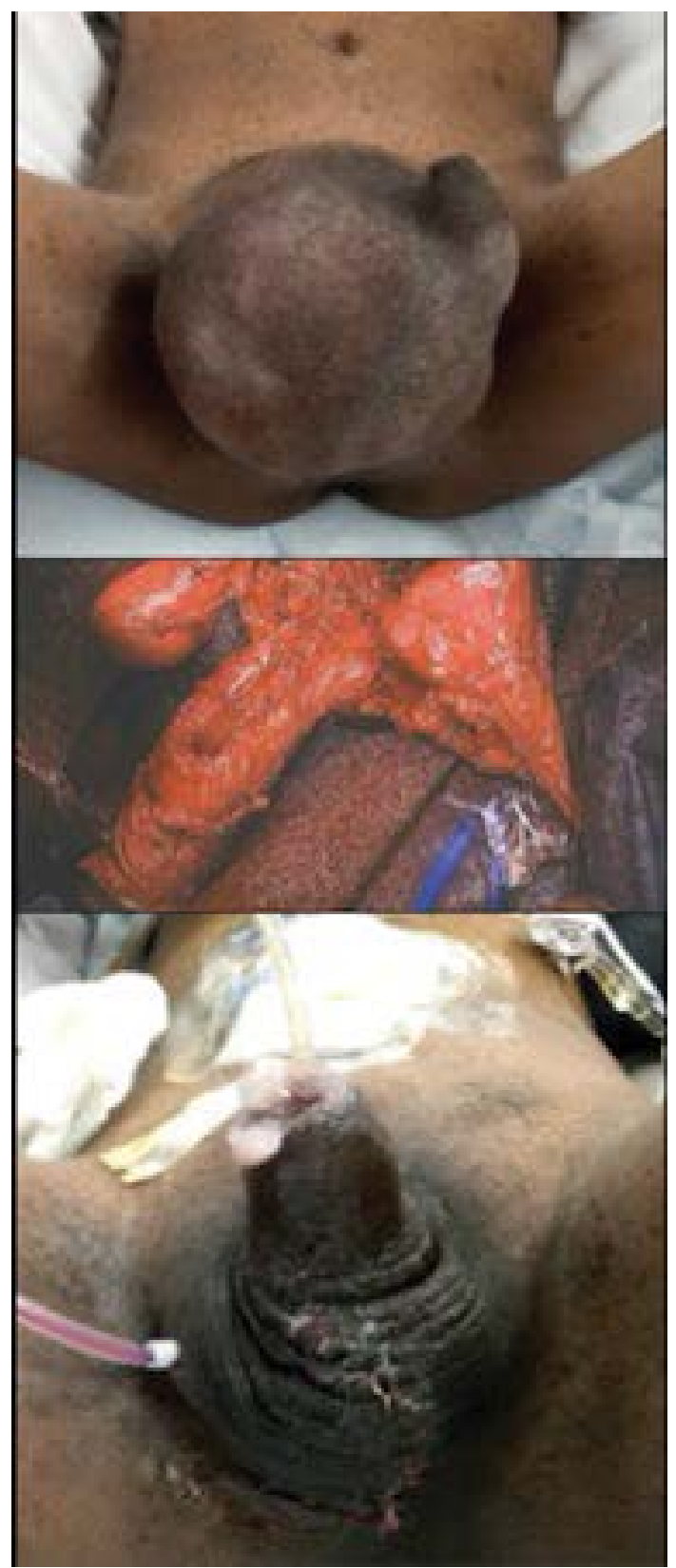

Figure 2: Pre, per and post-operative. sheath tumor. Urology was consulted at this time, as the patient suffered from discomfort and difficulty with ambulation. Further evaluation with pelvic magnetic resonance imaging $(\mathrm{MRI})$ revealed a large $9.8 \times 9.2 \times 8.5$ $\mathrm{cm}$ mass in the right perineal region near the base of the penis with areas of central necrosis, but without pelvic or inguinal lymph node involvement (Figure 1). Physical examination revealed a large, indurated mass at the right penile base, fixed to the pubis, pushing the penile shaft to the left and the right testis inferiorly.

The patient underwent surgical excision of the penile mass. The mass originated from the right penile neurovascular bundle, invaded the right corpus cavernosum, and draped over the dorsal penis to surround the left neurovascular bundle as well. It invaded the symphysis pubis and pelvic floor muscles. The urethra and bilateral spermatic cords were spared. The right neurovascular bundle was sacrificed, along with a portion of the tunica albuginea of the right corpus cavernosum. Margins were negative on the symphysis pubis and pelvic floor, but total penectomy would have been necessary for negative margins on the penis. Given the patient's comorbidities, maximum excision of the tumor for palliation while maintaining minimum penile anatomy was performed with right erectile body reconstruction and scrotoplasty (Figure 2).

Histopathological and immunohistochemical staining were consistent with a high grade MPNST (Figure 3) Tumor cells were present at the resection margins and tumor necrosis was estimated at $10 \%$. The lymph nodes were not assessed, however no lymphovascular invasion was noted.

The case was discussed at the pediatric tumor board and the decision was made for the patient to undergo adjuvant radiotherapy and targeted therapy for palliation. The patient received six weeks of radiotherapy (55.8 Gy) to the penile mass. Targeted therapy with 

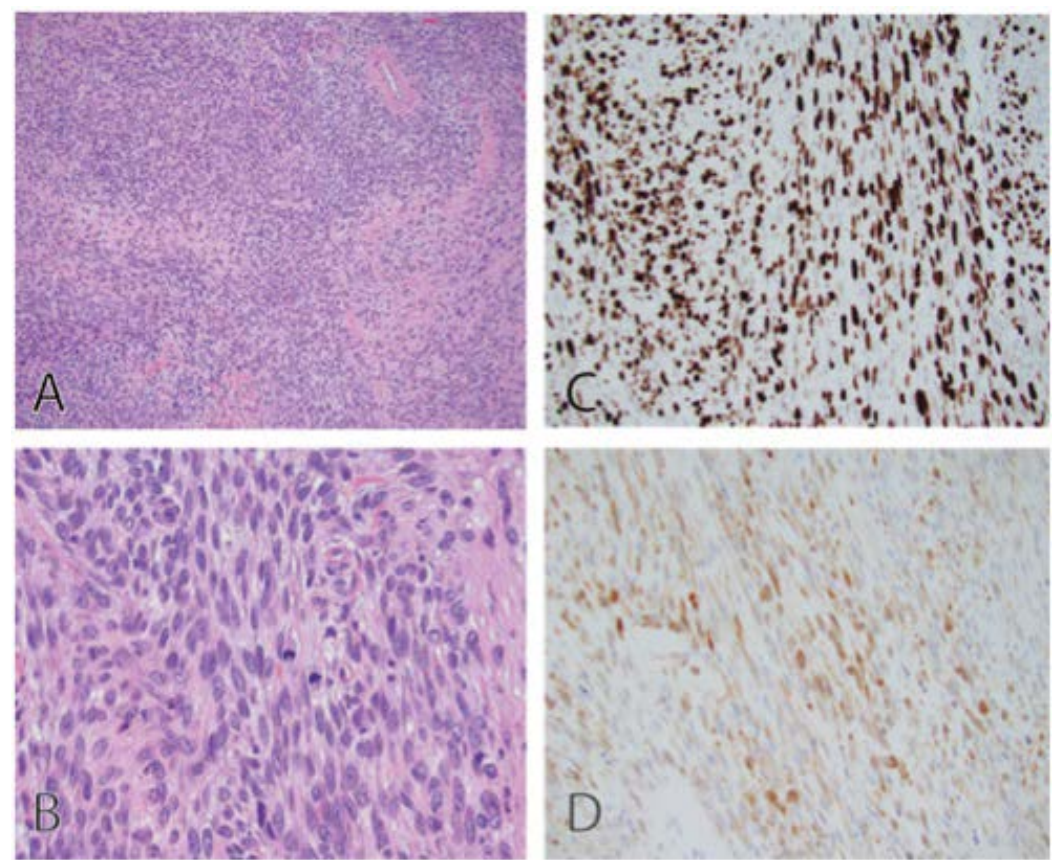

Figure 3: Histology (A-B) and immunohistochemical stains (C-D).

Table 1: Reported cases of penile MPNST in the current literature [11-16].

\begin{tabular}{|c|c|c|c|c|c|c|}
\hline Author (year) & NF1 & $\begin{array}{l}\text { Age at } \\
\text { diagnosis } \\
\text { (years) }\end{array}$ & Size $(\mathrm{cm})$ & Location & Treatment & Outcome \\
\hline Dehner (1970) & Yes & 15 & 4.0 & Prepuce, glans & Partial excision & Lost to follow-up \\
\hline Dehner (1970) & Yes & 2 & 2.5 & Dorsal shaft & Excision & $\begin{array}{l}\text { Recurrence }(4 x) \text { at same } \\
\text { location in } 2 \text { years }\end{array}$ \\
\hline $\begin{array}{l}\text { Aloi } \\
(1995)\end{array}$ & No & 58 & 1 & Glans & Excision & $\begin{array}{l}\text { No metastasis at 1-year } \\
\text { follow-up }\end{array}$ \\
\hline van Eck (2006) & $\begin{array}{l}\text { Not } \\
\text { reported }\end{array}$ & 74 & Not reported & Not reported & Partial penile amputation & $\begin{array}{l}\text { - Inguinal metastasis at } \\
7 \text { years } \rightarrow \text { resection } \& \\
\text { radiation }(64.8 \mathrm{~Gy}) \\
\text { - Gall bladder metastasis at } \\
8 \text { years } \rightarrow \text { cholecystectomy } \\
\text { - Multiple brain metastasis } \\
\text { at } 9 \text { years } \rightarrow \text { gamma knife } \\
\text { surgery }(2 x)\end{array}$ \\
\hline Mortell (2007) & No & 3 & $1.3 \times 0.7 \times 0.4$ & Dorsal shaft & $\begin{array}{l}\text { Excision with positive } \\
\text { margins } \rightarrow \text { re-resection at } 3 \\
\text { months }\end{array}$ & $\begin{array}{l}\text { - Local recurrence }(2 x) \& \\
\text { resection }(2 x) \text { at } 4 \text { and } 4.5 \\
\text { years } \\
\text { - No recurrence at } 5.5 \\
\text { years }\end{array}$ \\
\hline $\begin{array}{l}\text { Parekh } \\
\text { (2013) }\end{array}$ & No & 14 months & $5.4 \times 3.7 \times 3.8$ & Base of penis & $\begin{array}{l}\text { - Chemotherapy ( } 2 \text { cycles } \\
\text { doxorubicin \& ifosfamide) } \\
\text { with } 35 \% \text { growth } \\
\text { - Total penectomy (+ } \\
\text { margins) } \\
\text { - Radiation ( } 5580 \text { cGy total) }\end{array}$ & $\begin{array}{l}\text { No recurrence or } \\
\text { metastasis at } 9 \text { months }\end{array}$ \\
\hline $\begin{array}{l}\text { Kaur } \\
(2015)\end{array}$ & No & 38 & $3.6 \times 2.3 \times 2.2$ & Base of penis & $\begin{array}{l}\text { - Resection ( } 3 \mathrm{~mm} \text { margin) } \\
\rightarrow \text { corpora excision } \\
\text { - Radiation ( } 60 \text { Gy in } 30 \\
\text { fractions) } \\
\text { - Chemotherapy ( } 6 \text { cycles } \\
\text { doxorubicin \& ifosfamide) }\end{array}$ & $\begin{array}{l}\text { No recurrence or } \\
\text { metastasis at } 3 \text { months }\end{array}$ \\
\hline
\end{tabular}

everolimus was initiated, as the penile mass developed while the patient was being treated with pazopanib for the mediastinal lesion.
At his 3-month post-surgical follow-up, physical examination revealed a well-healed uncircumcised penis and scrotum. A non-tender subtle protuberance supe- 
rior to the pubic bone at the right penile base was felt. The patient reported no difference in sensation on either side of the penis.

Unfortunately, the penile mass started to grow again. In light of multiple late effects from previous therapies, the family did not wish to pursue further aggressive therapy. The patient continued to undergo palliative radiation ( $14 \mathrm{~Gy}$ ) to the penile mass. Sadly, he passed 16 months after surgery due to disease progression.

\section{Discussion}

Despite aggressive intervention, the prognosis of MPNST remains poor. In general, MPNST has a $50 \%$ rate of local recurrence at 12 months and a $50 \%$ rate of metastasis at 24 months. The overall estimated mean survival in MPNST is 45 months, with worse prognosis associated with male gender, age greater than 7 years, tumor size greater than $5 \mathrm{~cm}$, high grade lesion, more than $25 \%$ necrosis, and positive surgical margins [1]. An even poorer prognosis is associated with the presence of NF1, as they typically present with more severe clinical features [3].

An international consensus statement on the treatment of MPNST released in 2002 recommended wide surgical resection followed by radiotherapy for local control and delay in onset of recurrence, especially in the setting of positive margins [4]. A cumulative dose of $60 \mathrm{~Gy}$ or greater has resulted in improved local control in MPNST [5]. Chemotherapy is typically reserved for metastatic disease, though its role is not yet defined. Single agent anthracyclines (doxorubicin) or anthracycline-based combinations (doxorubicin and ifosfamide) have traditionally been the initial standard chemotherapy for advanced or metastatic STS [6,7]. Comparison studies yield a response rate of $21 \%$, median progression-free survival of 17 weeks and overall survival of 48 weeks.

Since the 2002 international consensus statement cited above, there have been substantial advancements in MPNST-specific molecular and genomic studies. One of the first targeted therapies studied was the EGFR inhibitor erlotinib. Agents targeting the rat sarcoma viral oncogene homologue (RAS)-mitogen activated protein kinase (MAPK) and mammalian target of rapamycin (mTOR), have been recent emerging areas of research [8]. In-vitro MPNST antitumor activity has been demonstrated with everolimus, an mTOR inhibitor [9]. Combination therapy including targeted therapy is a new direction for this aggressive STS [10].

Limited data exists in the literature regarding the management of MPNST of the penis precisely. Previously reported cases utilizing a combination of surgery, radiation and chemotherapy yield variable outcomes (Table 1).

In summary, malignant peripheral nerve sheath tumors are rare but highly aggressive soft tissue sarcomas, especially in the setting of neurofibromatosis, that require prompt diagnosis and complete surgical excision, with potential benefit in adjuvant radiation and chemotherapy or targeted therapy. The penile location poses a particular anatomical and functional challenge.

\section{References}

1. Ducatman BS, Scheithauer BW, Piepgras DG, Reiman HM, Ilstrup DM (1986) Malignant peripheral nerve sheath tumors. A clinicopathologic study of 120 cases. Cancer 57: 2006-2021.

2. Evans DG, Baser ME, McGaughran J, Sharif S, Howard E, et al. (2002) Malignant peripheral nerve sheath tumours in neurofibromatosis 1. J Med Genet 39: 311-314.

3. Carli M, Ferrari A, Mattke A, Zanetti I, Casanova M, et al. (2005) Pediatric malignant peripheral nerve sheath tumor: The Italian and German soft tissue sarcoma cooperative group. J Clin Oncol 23: 8422-8430.

4. Ferner RE, Gutmann DH (2002) International consensus statement on malignant peripheral nerve sheath tumors in neurofibromatosis. Cancer Res 62: 1573-1577.

5. Wong WW, Hirose T, Scheithauer BW, Schild SE, Gunderson LL (1998) Malignant peripheral nerve sheath tumor: Analysis of treatment outcome. Int J Radiat Oncol Biol Phys 42: 351-360.

6. Sarcoma Meta-analysis Collaboration (SMAC) (2000) Adjuvant chemotherapy for localised resectable soft tissue sarcoma in adults. Cochrane Database Syst Rev.

7. Demetri GD, Elias AD (1995) Results of single-agent and combination chemotherapy for advanced soft tissue sarcomas. Implications for decision making in the clinic. Hematol Oncol Clin North Am 9: 765-785.

8. Varin J, Poulain L, Hivelin M, Nusbaum P, Hubas A, et al. (2016) Dual mTORC1/C inhibition induces anti-proliferative effect in NF1-associated plexiform neurofibroma and malignant peripheral nerve sheath tumor cells. Oncotarget 7 : 35753-35767.

9. Endo M, Yamamoto H, Setsu N, Kohashi K, Takahashi Y, et al. (2013) Prognostic significance of AKT/mTOR and MAPK pathways and antitumor effect of mTOR inhibitor in NF1-related and sporadic malignant peripheral nerve sheath tumors. Clin Cancer Res 19: 450-461.

10. Bradford D, Kim A (2015) Current treatment options for malignant peripheral nerve sheath tumors. Curr Treat Options Oncol 16: 328.

11. Aloi F, Modi G, Solaroli C (1995) Malignant schwannoma of the glans penis. Hautarzt 46: 656-659.

12. Dehner LP, Smith BH (1970) Soft tissue tumors of the penis: A clinicopathologic study of 46 cases. Cancer 25: 14311447.

13. Mortell A, Amjad B, Breatnach F, Devaney D, Puri P (2007) Penile malignant peripheral nerve sheath tumour (schwannoma) in a three-year-old child without evidence of neurofibromatosis. Eur J Pediatr Surg 17: 428-430.

14. Van Eck A, Horstmann GA (2006) Gamma knife surgery for multiple brain metastases from a malignant schwannoma of the penis. J Neurosurg 105: 238-240.

15. Parekh N, Cockrell E, McMahon D (2013) Malignant peripheral nerve sheath tumor of the penis: A case report and review of the literature. Urology 81: 1067-1068.

16. Kaur J, Madan R, Singh L, Sharma DN, Julka PK, et al. (2014) Malignant peripheral nerve sheath tumour of penis. Andrologia 47: 333-335. 